ARTICLE OPEN

\title{
Tools for studying growth patterns and chemical dynamics of aggregated Pseudomonas aeruginosa exposed to different electron acceptors in an alginate bead model
}

\author{
Majken Sønderholm (iD) , Klaus Koren (D) ${ }^{2}$, Daniel Wangpraseurt ${ }^{2,3}$, Peter Østrup Jensen ${ }^{1,4}$, Mette Kolpen (iD ${ }^{4}$, Kasper Nørskov Kragh ${ }^{1}$, \\ Thomas Bjarnsholt (iD ${ }^{1,4}$ and Michael Kühl id ${ }^{2,5}$
}

In chronic infections, bacterial pathogens typically grow as small dense cell aggregates embedded in a matrix consisting of, e.g., wound bed sludge or lung mucus. Such biofilm growth mode exhibits extreme tolerance towards antibiotics and the immune defence system. The bacterial aggregates are exposed to physiological heterogeneity and $\mathrm{O}_{2}$ limitation due to steep chemical gradients through the matrix, which is are hypothesised to contribute to antibiotic tolerance. Using a novel combination of microsensor and bioimaging analysis, we investigated growth patterns and chemical dynamics of the pathogen Pseudomonas aeruginosa in an alginate bead model, which mimics growth in chronic infections better than traditional biofilm experiments in flow chambers. Growth patterns were strongly affected by electron acceptor availability and the presence of chemical gradients, where the combined presence of $\mathrm{O}_{2}$ and nitrate yielded highest bacterial growth by combined aerobic respiration and denitrification.

npj Biofilms and Microbiomes (2018)4:3; doi:10.1038/s41522-018-0047-4

\section{INTRODUCTION}

Bacterial biofilms are ubiquitous in most natural habitats, where they play an integral role in the cycling of elements. However, biofilms are also associated with a wide range of harmful effects ranging from biofouling of ship hulls and drainpipes to the formation of biofilms on medical implants and indwelling devices. ${ }^{1}$ In chronic infections such as diabetic and venous leg ulcers or in the lungs of patients suffering from the genetic disorder cystic fibrosis (CF), ${ }^{2,3}$ biofilms grow as small dense cell aggregates devoid of surface association, ${ }^{4,5}$ in a matrix of exopolymeric substance consisting of polysaccharides, proteins, and eDNA. ${ }^{6-9}$ Such bacterial aggregates are embedded in a secondary matrix composed of, e.g., wound bed sludge or CF lung mucus. Bacterial aggregates exhibit physiological heterogeneity due to steep chemical gradients forming through the secondary matrix and into the biofilm. ${ }^{10,11}$ In particular, molecular oxygen $\left(\mathrm{O}_{2}\right)$ has been shown to reach hypoxic and anoxic levels within the outer $50-100 \mu \mathrm{m}$ of biofilms and chronic wounds. ${ }^{12-14}$ Steep $\mathrm{O}_{2}$ gradients are also a recognised feature of chronic infections, ${ }^{13,15-}$ 17 where activated polymorphonuclear leucocytes persistently accumulate around the bacterial aggregates ${ }^{4,18}$ leading to strong depletion of $\mathrm{O}_{2}$ due to formation of reactive oxygen species. ${ }^{19,20}$ Such complexity of the chemical landscape is believed to result in heterogeneous growth patterns, and the establishment of bacterial subpopulations exhibiting particular metabolic activities. $^{21}$ This in turn can have an impact on the efficacy of antibiotic treatment as several studies have shown that $\mathrm{O}_{2}$ limitation is correlated to increased antibiotic tolerance of biofilms. ${ }^{10-12,22}$
The opportunistic pathogenic bacterium Pseudomonas aeruginosa is a key model organism for the study of biofilm infections, and it has been isolated from both chronic wounds and chronically infected lungs of CF patients. In order to gain further insight to the biofilm mode of growth of $P$. aeruginosa, several optical methods can be applied for visualising growth patterns and biofilm structure. The standard method of confocal laser scanning microscopy (CLSM) of stained or fluorescently tagged $P$. aeruginosa provides very localised information on biomass distribution (at $\mu \mathrm{m}$ scale). In combination with quantitative peptide nucleic acid fluorescence in situ hybridisation (PNAFISH) ${ }^{21,23}$ CLSM can also be applied to quantify the growth potential $^{21}$ by treating bacterial cells with PNA-FISH probes specific for $P$. aeruginosa $16 \mathrm{~S}$ rRNA. ${ }^{24}$ While providing highresolution data on bacterial growth, this method is based on fixed samples and is therefore an invasive technique. When aiming to unravel structural biofilm properties at mesoscopic to macroscopic levels (10 $\mu \mathrm{m}-\mathrm{mm}$ length scale), optical coherence tomography (OCT) is a suitable alternative imaging technique. ${ }^{25}$ OCT employs near-infrared radiation (NIR) and provides a non-invasive alternative to light microscopy, enabling high-resolution 3D scanning of larger $\left(\mathrm{mm}^{3}\right.$ to $\left.\mathrm{cm}^{3}\right)$ biofilm volumes in near-real time. ${ }^{26-28} \mathrm{As}$ previously mentioned, bacterial aggregates are exposed to chemical and physiological heterogeneity due to steep $\mathrm{O}_{2}$ gradients. To further elucidate this aspect, microsensors can be used to investigate the chemical environment in a minimal invasive fashion. ${ }^{29}$ Microsensors are available for several analytes including $\mathrm{O}_{2}$ and nitrous oxide $\left(\mathrm{N}_{2} \mathrm{O}\right)$, a key intermediate product of denitrification. ${ }^{30}$ Another approach is to use chemical imaging

\footnotetext{
${ }^{1}$ Department of Immunology and Microbiology, Faculty of Health and Medical Sciences, University of Copenhagen, Blegdamsvej 3B, DK-2200 Copenhagen N, Denmark; ${ }^{2}$ Marine Biology Section, Department of Biology, University of Copenhagen, Strandpromenaden 5, DK-3000 Helsingør, Denmark; ${ }^{3}$ Department of Chemistry, University of Cambridge,

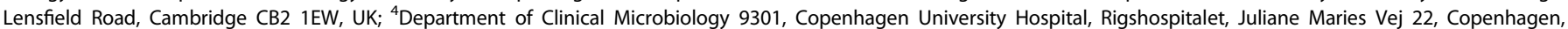
Denmark and ${ }^{5}$ Climate Change Cluster, University of Technology Sydney, Broadway, NSW 2007, Australia Correspondence: Thomas Bjarnsholt (tbjarnsholt@sund.ku.dk) or Michael Kühl (mkuhl@bio.ku.dk)
}

Received: 31 August 2017 Revised: 7 January 2018 Accepted: 24 January 2018

Published online: 19 February 2018 
with optical sensors (either immobilised in sensor films or particles) to visualise the chemical microenvironments in biofilms. ${ }^{31-34}$

Biofilms are often studied in vitro using continuous flow cell systems, wherein biofilms are grown attached to a surface and can exhibit a variety of structural morphologies including mushroomshaped structures. ${ }^{35}$ However, in CF lungs and chronic wounds $P$. aeruginosa grows in dense suspended aggregates separated by a secondary matrix and with no attachment to a solid substrate or surface. ${ }^{4}$ The typical growth mode and biofilm shapes observed in flow chambers are thus not representative of the observed in vivo growth patterns of biofilms associated with chronic infections. To better mimic the in vivo conditions of $P$. aeruginosa in chronic infections, we recently employed an alginate bead model, ${ }^{14}$ wherein the bacteria form dense, spatially segregated micro colonies similar in size and structure to $P$. aeruginosa aggregates observed ex vivo in lungs from CF patients ${ }^{21}$ and chronic wounds. ${ }^{4}$

$P$. aeruginosa can grow anaerobically by performing arginine fermentation or using alternative electron acceptors ${ }^{36-38}$ and there is increasing evidence that $P$. aeruginosa can utilise the high physiological $\mathrm{NO}_{3}{ }^{-}$and $\mathrm{NO}_{2}{ }^{-}$levels in the $\mathrm{CF}$ lungs to grow under $\mathrm{O}_{2}$ limitation by performing denitrification. ${ }^{39,40}$ In this study, we investigated $P$. aeruginosa aggregate growth in alginate beads with different $\mathrm{O}_{2}$ and $\mathrm{NO}_{3}{ }^{-}$availability mimicking physiological conditions encountered in the chronic infections. ${ }^{41,42}$ The bacterial biomass, growth rate, and chemical microenvironment in the beads was characterised using a novel combination of OCT, CLSM, PNA-FISH, viable cell counts, $\mathrm{O}_{2}$ and $\mathrm{N}_{2} \mathrm{O}$ microsensor analysis, as well as first attempts of chemical $\mathrm{O}_{2}$ imaging. We found significant effects of electron acceptor availability on the growth pattern and metabolic activity of $P$. aeruginosa forming in vivo-like microcolonies in the alginate bead model, and discuss the implications of our results for better treatment of chronic infections.

\section{RESULTS}

Optical coherence tomography

OCT facilitated non-invasive macroscopic imaging of the alginate beads (Supplementary Fig. S1A, B), wherein light scattering bacterial aggregates were identified by their high OCT signal. Due to dense growth of bacterial aggregates in the bead periphery, the vertical OCT signal attenuation was rapid and at about $200 \mu \mathrm{m}$ below the bead surface the OCT signal approached that of the OCT signal of pure alginate (Supplementary Fig. S2). The OCT dB signal from the outermost peripheral $150 \mu \mathrm{m}$ of the beads could thus be used as a proxy for bacterial biomass distribution. The OCT dB signal of anoxic beads (without $\mathrm{NO}_{3}{ }^{-}$) was similar to the blank control (without bacteria), thus suggesting no or very minor growth (Fig. 1). In contrast, the OCT signal from anoxic beads with $\mathrm{NO}_{3}{ }^{-}$was significantly higher relative to the control after $48 \mathrm{~h}(p=0.035)$. Normoxic beads and normoxic beads supplemented with $\mathrm{NO}_{3}{ }^{-}$gave rise to the strongest OCT signal, indicative of intense growth and biomass accumulation in the bead periphery (Fig. 1, S1).

\section{Microscopy}

Bacterial growth and organisation in the alginate beads was visualised microscopically by CLSM using green fluorescent protein (GFP)-tagged $P$. aeruginosa (Fig. 2). In normoxic beads, $P$. aeruginosa showed peripheral growth (growth in the outermost $\sim 100 \mu \mathrm{m}$ of the bead) of bacterial microcolonies after 24 and $48 \mathrm{~h}$ (Fig. 2b). Normoxic growth in the presence of $\mathrm{NO}_{3}{ }^{-}$resulted in a very intense growth, with larger aggregates in the periphery than observed under anoxic growth of $P$. aeruginosa in the presence of $\mathrm{NO}_{3}{ }^{-}$. Moreover, $48 \mathrm{~h}$ normoxic growth of $P$. aeruginosa with $\mathrm{NO}_{3}{ }^{-}$resulted in a heterogeneous growth pattern, with bacterial

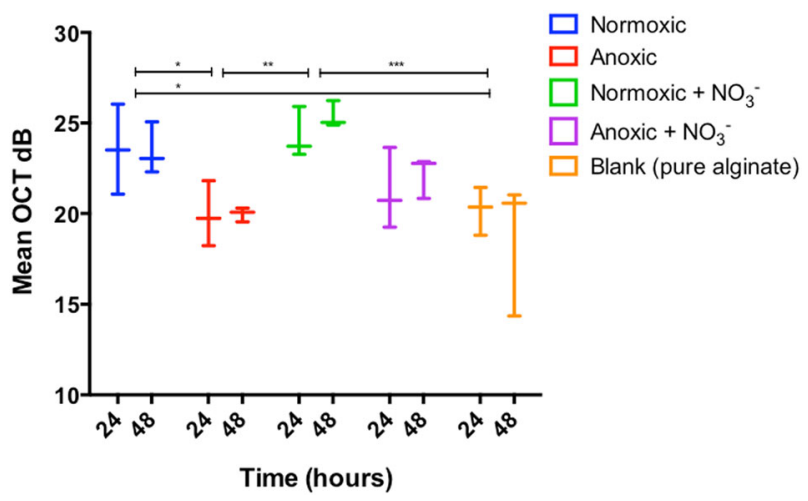

Fig. 1 OCT signal intensity $(\mathrm{dB})$ of alginate beads over $48 \mathrm{~h}$ of incubation. The OCT signal was averaged for an area covering a vertical depth of $150 \mu \mathrm{m}$ (from the bead surface into the interior) and a lateral width of $100 \mu \mathrm{m}$ and was used as a proxy for bacterial growth (see "Methods"). Bars represent average \pm standard errors of the means from three replicates. Significant differences as indicated. ${ }^{*} p>0.05 ;{ }^{* *} p \leq 0.01 ;{ }^{* * *} p \leq 0.001$

microcolonies decreasing in size with distance from the surface of the alginate bead (Fig. 2a). Anoxic beads with $\mathrm{NO}_{3}{ }^{-}$showed a homogeneous distribution of aggregate size in the bead after 24 $\mathrm{h}$, but also exhibited signs of a more heterogeneous aggregate size distribution after $48 \mathrm{~h}$ growth with largest aggregates closer to the bead surface (Fig. 2c). No growth was observed in anoxic beads without alternative electron acceptors at $48 \mathrm{~h}$ (Fig. 2d), which was supported by the OCT imaging results.

Microscopy combined with quantitative PNA-FISH

The mean fluorescence intensity used here as a proxy for the growth potential (the maximum possible growth rate) of $P$. aeruginos $a^{21}$ was quantified and plotted for each of the growth conditions. In normoxic beads, we found that $\mathrm{NO}_{3}{ }^{-}$supplementation induced significantly deeper growth of $P$. aeruginosa aggregates (Fig. 3a). The median growth depth (interquartile range, IQR) was $51.6(17.4-92.0) \mu \mathrm{m}$ vs. $20.0(2.0-45.0) \mu \mathrm{m}(p<$ 0.0001 ) below the alginate bead surface. When $\mathrm{NO}_{3}{ }^{-}$was present, the median growth depth (IQR) was comparable under normoxic vs. anoxic conditions, i.e., $51.6(17.4-92.0) \mu \mathrm{m}$ vs. 41.6 (14.2-88.6) $\mu \mathrm{m}(p=0.481)$.

In normoxic beads with $\mathrm{NO}_{3}{ }^{-}$, the growth potential of $P$. aeruginosa was significantly higher after $24 \mathrm{~h}$ than after $48 \mathrm{~h}$ (10212 FU \pm 3298 FU vs. $7141 \mathrm{FU} \pm 1470 \mathrm{FU} ; p<0.001$ ). Furthermore, we found a significantly higher growth depth at $24 \mathrm{~h}$ vs. 48 $h$, with a median growth depth (IQR) of $62.9(25.9-98.0) \mu \mathrm{m}$ vs. $38.8(11.3-70.3) \mu \mathrm{m}(p=0.023)$ below the alginate bead surface (Fig. 3a). Growth depth in normoxic beads without $\mathrm{NO}_{3}{ }^{-}$did not differ between the two time points $(p=0.139)$, but the growth potential, as estimated by mean fluorescence, was significantly higher at $24 \mathrm{~h}$ as compared to $48 \mathrm{~h}(9243 \pm 2433$ vs. $6586 \pm 1614$; $p<0.001$ ) (Fig. 3b). In anoxic beads with $\mathrm{NO}_{3}{ }^{-}$, there was no significant difference in neither growth depth $(p=0.761)$ or in growth potential $(p=0.124)$ at $24 \mathrm{~h}$ vs. $48 \mathrm{~h}$, and the growth potential remained high (9258 FU $\pm 1865 \mathrm{FU}$ vs. $8750 \mathrm{FU} \pm 1780$ FU) both after 24 and $48 \mathrm{~h}$ (Fig. 3c).

When correlating growth potential to growth depth, we found no statistically significant correlation under any conditions. It was not possible to prepare paraffin slices for anoxic beads without $\mathrm{NO}_{3}{ }^{-}$, but as previously shown $P$. aeruginosa failed to grow under these conditions (Figs. 2, 4). 
24 hours
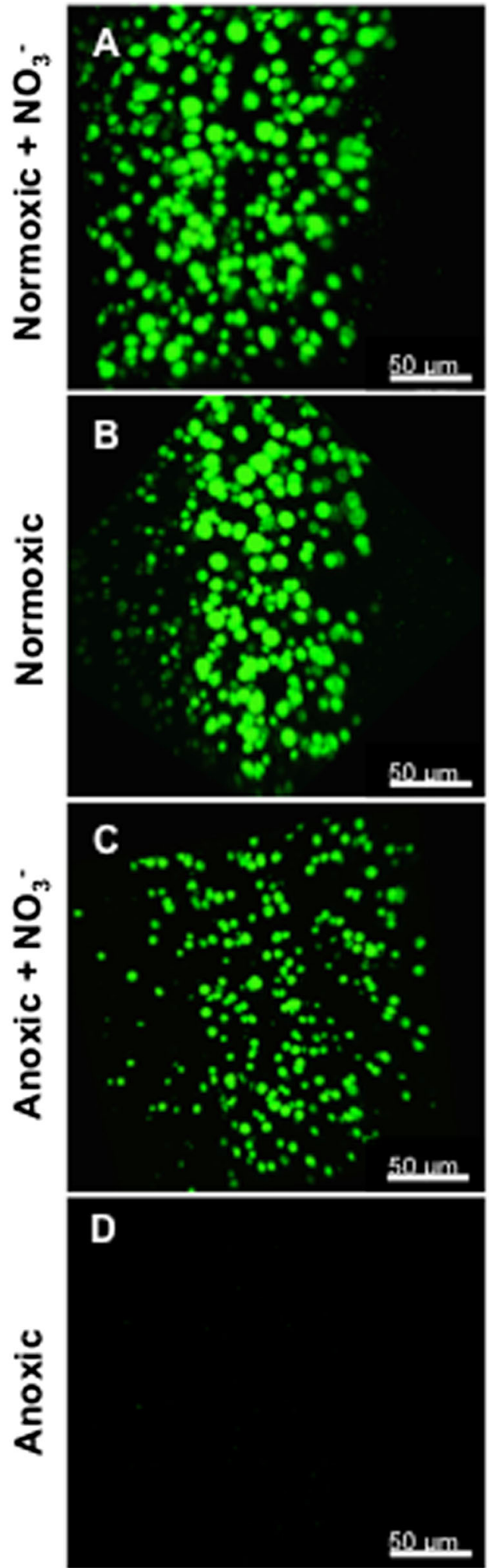

48 hours
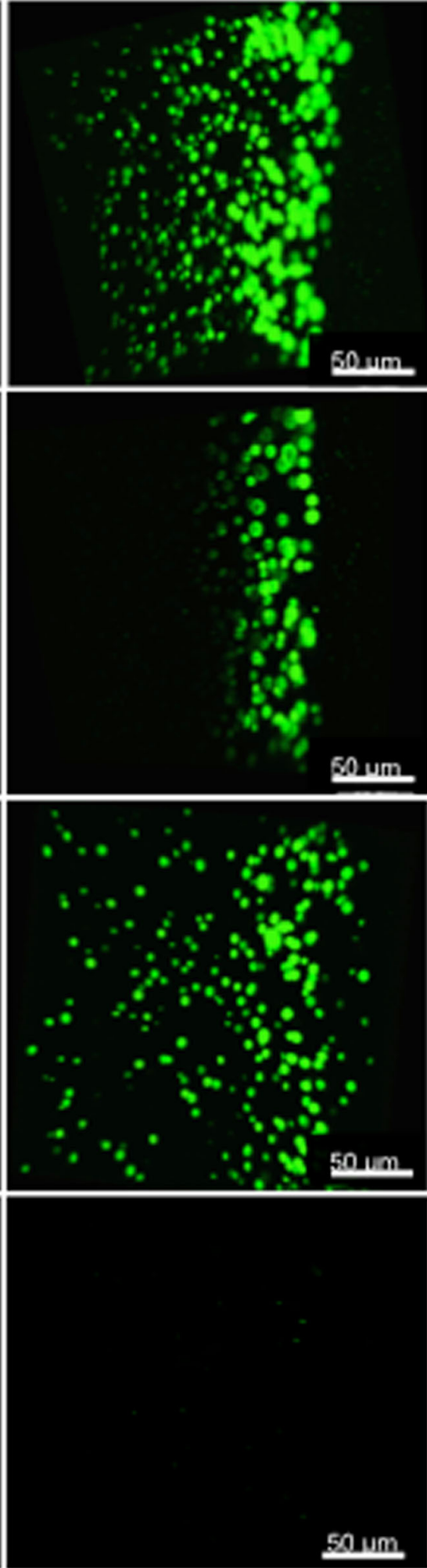

Fig. $2400 \times$ CLSM images of the growth dynamics of GFP-tagged $P$. aeruginosa grown under different conditions after 24 and $48 \mathrm{~h}$. a Normoxic growth in the presence of $\mathrm{NO}_{3}{ }^{-}$resulted in intense and deep growth with a tendency to form smaller aggregates in the deeper parts over time. b Normoxic growth resulted in peripheral growth over time. c Anoxic growth with $\mathrm{NO}_{3}{ }^{-}$also supported growth, but with apparently smaller aggregates. d Anoxic growth without $\mathrm{NO}_{3}{ }^{-}$did not support growth. The edge of the alginate bead is oriented to the right in the images. Size of scale bars: $50 \mu \mathrm{m}$ 

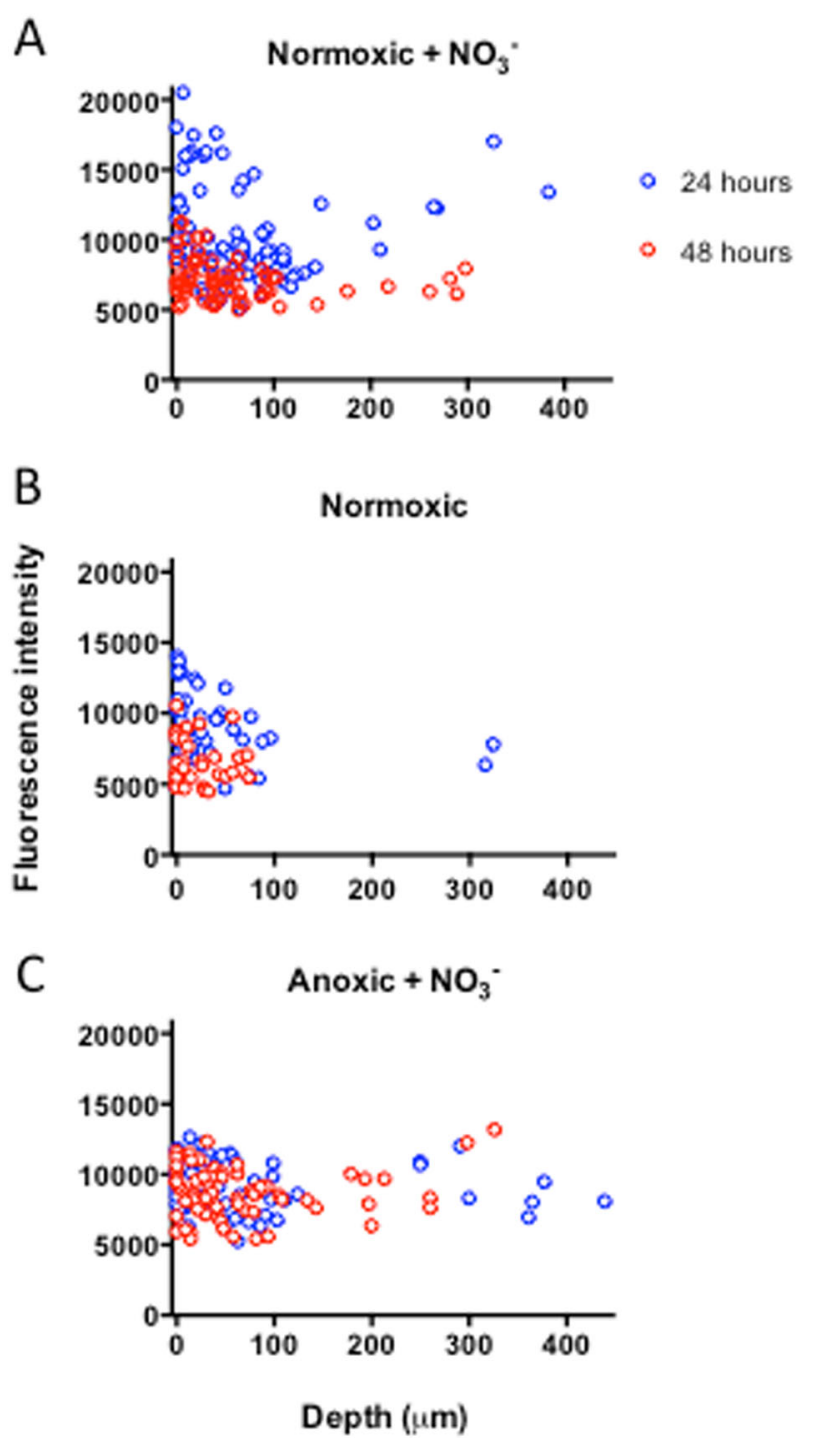

Fig. 3 Growth potential of $P$. aeruginosa grown in alginate beads expressed as mean fluorescence intensity. a Normoxic growth conditions supplemented with $\mathrm{NO}_{3}{ }^{-}$, b normoxic growth conditions without $\mathrm{NO}_{3}{ }^{-}$, and $\mathbf{c}$ anoxic growth conditions in the presence of $\mathrm{NO}_{3}{ }^{-}$. P. aeruginosa was fluorescently labelled with Texas-Redconjugated PNA-FISH probe tagging ribosomes, imaged by CLSM and quantification of intensity was performed by Imaris

\section{Colony-forming unit (CFU)}

All bead cultures were initiated with a CFU-defined cell density of $\sim 10^{7}$ cells per bead (mean $1.175 \times 10^{7}$; range $8.67 \times 10^{6}-1.483 \times$ $10^{7}$ ) (Fig. 4). While CFU values remained stable in the anoxic culture without $\mathrm{NO}_{3}{ }^{-}$, the other growth conditions facilitated a significant increase in CFU of $1-2$ log units from 0 to $24 \mathrm{~h}$, which then remained constant between 24 and $48 \mathrm{~h}$. The highest CFU was observed for the growth condition with both $\mathrm{O}_{2}$ and $\mathrm{NO}_{3}{ }^{-}$ available in the alginate beads $(p<0.0001)$.

\section{Microsensor measurements}

The $\mathrm{O}_{2}$ concentration profiles measured in normoxic alginate beads (without $\mathrm{NO}_{3}{ }^{-}$) after $24 \mathrm{~h}$ incubation showed the presence of an oxygenated zone in the peripheral $200 \mu \mathrm{m}$ with a steep decline in the $\mathrm{O}_{2}$ concentration and an inner hypoxic zone (Fig. 5a). After $48 \mathrm{~h}$, the slope of the profile decreased, indicating an overall decrease in $\mathrm{O}_{2}$ respiration rate from 24 to $48 \mathrm{~h}$ (Fig. 5a),

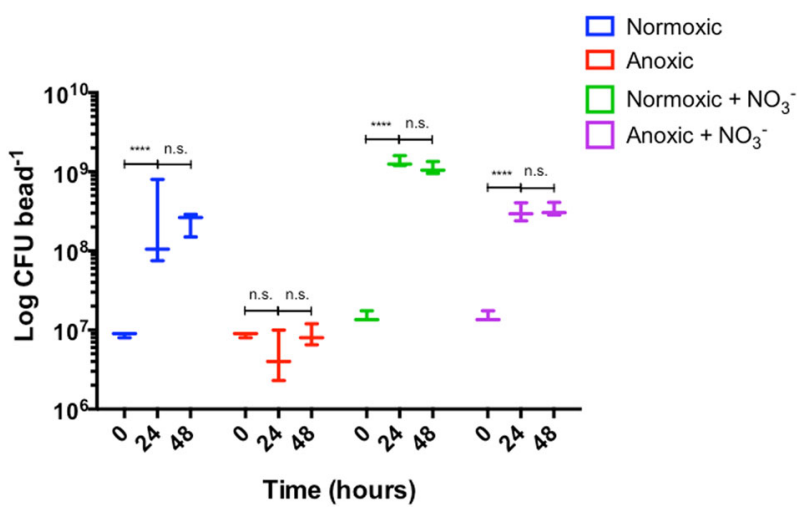

Fig. 4 Viable cell counts as colony-forming units (CFU) from dissolved alginate beads after 0, 24, and $48 \mathrm{~h}$. Highest CFU was observed for normoxic beads supplemented with $\mathrm{NO}_{3}{ }^{-}$. No change in CFU over time for the anoxic group was observed. Bars represent average \pm standard errors of the means from three replicates. Significant differences as indicated. n.s. not significant; ${ }^{* * *} p \leq$ 0.0001

leading to more $\mathrm{O}_{2}$ accumulation in the beads over time. No $\mathrm{N}_{2} \mathrm{O}$ production was detected in normoxic grown alginate beads without $\mathrm{NO}_{3}{ }^{-}$(Fig. 5a). In normoxic alginate beads supplemented with $\mathrm{NO}_{3}{ }^{-}$, the maximal $\mathrm{N}_{2} \mathrm{O}$ concentration was detected in the lower, hypoxic zone (Fig. 6b). Contrary to normoxic beads (without $\left.\mathrm{NO}_{3}{ }^{-}\right), \mathrm{O}_{2}$ profiles in $\mathrm{NO}_{3}{ }^{-}$supplemented beads were stable between 24 and $48 \mathrm{~h}$, whereas $\mathrm{N}_{2} \mathrm{O}$ production decreased (Fig. 6b). $\mathrm{N}_{2} \mathrm{O}$ profiles in anoxic beads with $\mathrm{NO}_{3}{ }^{-}$revealed an increasing $\mathrm{N}_{2} \mathrm{O}$ concentration throughout the bead, with a slight decrease in production after $48 \mathrm{~h}$ (Fig. 6a).

Fluxes of $\mathrm{O}_{2}$ and $\mathrm{N}_{2} \mathrm{O}$

We found a stable $\mathrm{O}_{2}$ flux into the normoxic beads supplemented with $\mathrm{NO}_{3}\left(3.18 \pm 0.66-3.19 \pm 0.84 \mathrm{nmol} \mathrm{O} \mathrm{Cm}^{-2} \mathrm{~min}^{-1}\right)$, and a tendency towards a decreasing $\mathrm{O}_{2}$ flux into normoxic beads (without $\mathrm{NO}_{3}{ }^{-}$) between 24 and $48 \mathrm{~h}(3.07 \pm 1.33-1.84 \pm 0.32 \mathrm{nmol}$ $\mathrm{O}_{2} \mathrm{~cm}^{-2} \mathrm{~min}^{-1}$ ). Calculations of the efflux of $\mathrm{N}_{2} \mathrm{O}$ from the alginate beads revealed a stable $\mathrm{N}_{2} \mathrm{O}$ efflux in anoxic beads with $\mathrm{NO}_{3}{ }^{-}$between 24 and $48 \mathrm{~h}\left(0.10 \pm 0.03-0.13 \pm 0.1 \mathrm{nmol} \mathrm{N}_{2} \mathrm{O}\right.$ $\mathrm{cm}^{-2} \mathrm{~min}^{-1}$ ), whereas the normoxic beads with $\mathrm{NO}_{3}{ }^{-}$showed a tendency towards a decrease in $\mathrm{N}_{2} \mathrm{O}$ efflux between 24 and $48 \mathrm{~h}$ $\left(0.21 \pm 0.06-0.09 \pm 0.03 \mathrm{nmol} \mathrm{N} \mathrm{N}_{2} \mathrm{~cm}^{-2} \mathrm{~min}^{-1}\right)$. None of the changes in flux over time were statistically significant.

$\mathrm{NO}_{3}{ }^{-}, \mathrm{NO}_{2}{ }^{-}$, and $\mathrm{N}_{2} \mathrm{O}$ dynamics in growth medium

Measurements of $\mathrm{NO}_{3}{ }^{-}$and $\mathrm{NO}_{2}{ }^{-}$concentrations in the $\mathrm{R} 2 \mathrm{~A}$ growth medium supplemented with $\mathrm{NO}_{3}{ }^{-}$showed that the initial concentration $(t=0)$ of $\mathrm{NO}_{3}{ }^{-}$in the medium was $10.450 \mu \mathrm{M} \pm 148$ $\mu \mathrm{M}$ (Fig. 6a), while no $\mathrm{NO}_{2}{ }^{-}$could be detected (Fig. 6b). After $24 \mathrm{~h}$, the $\mathrm{NO}_{3}{ }^{-}$concentration had declined significantly to $4.119 \pm 0.149$ and $3.319 \pm 0.191 \mu \mathrm{M}(p<0.0001)$ in the anoxic and normoxic cultures, respectively, and was completely depleted within $48 \mathrm{~h}$ (Fig. 6a). $\mathrm{No} \mathrm{NO}_{2}{ }^{-}$could be detected in the normoxic cultures, but in the anoxic cultures there was a significant accumulation of $\mathrm{NO}_{2}{ }^{-}$after $24 \mathrm{~h}(p<0.0001)$, which was depleted again after $48 \mathrm{~h}$ (Fig. 6b). When measuring the $\mathrm{N}_{2} \mathrm{O}$ concentrations directly in the growth medium with electrochemical sensors, we found no $\mathrm{N}_{2} \mathrm{O}$ in the growth medium without added $\mathrm{NO}_{3}{ }^{-}$(data not shown). In the anoxic culture flasks with $\mathrm{NO}_{3}{ }^{-}$addition (sealed airtight), denitrification led to an accumulation of $\mathrm{N}_{2} \mathrm{O}$ over time (Fig. $6 \mathrm{c}$ ). After $24 \mathrm{~h}$ of incubation, a $\mathrm{N}_{2} \mathrm{O}$ concentration of $140 \mu \mathrm{M}$ was measured in the medium, increasing to $225 \mu \mathrm{M}$ after $48 \mathrm{~h}$. In the normoxic culture with $\mathrm{NO}_{3}{ }^{-}, \mathrm{N}_{2} \mathrm{O}$ was measured at a concentration of $120 \mu \mathrm{M}$ after $24 \mathrm{~h}$, but only $1.5 \mu \mathrm{M}$ after $48 \mathrm{~h}$. 
A

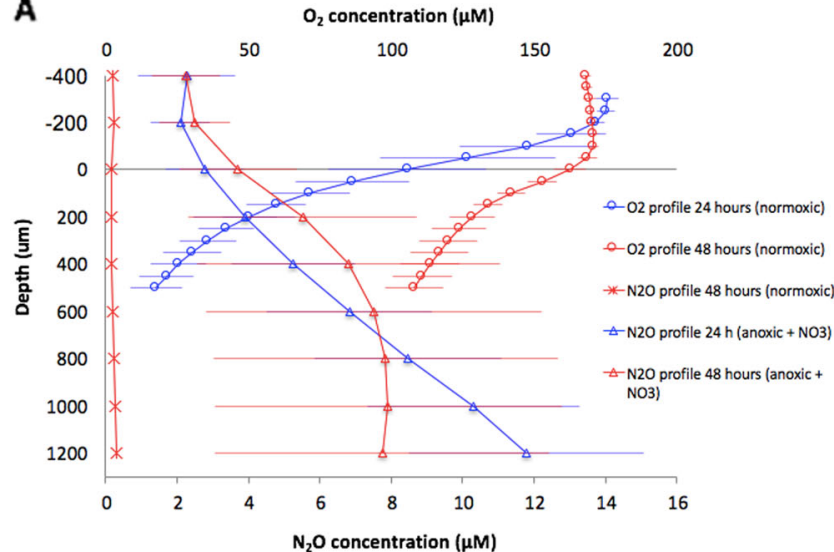

B

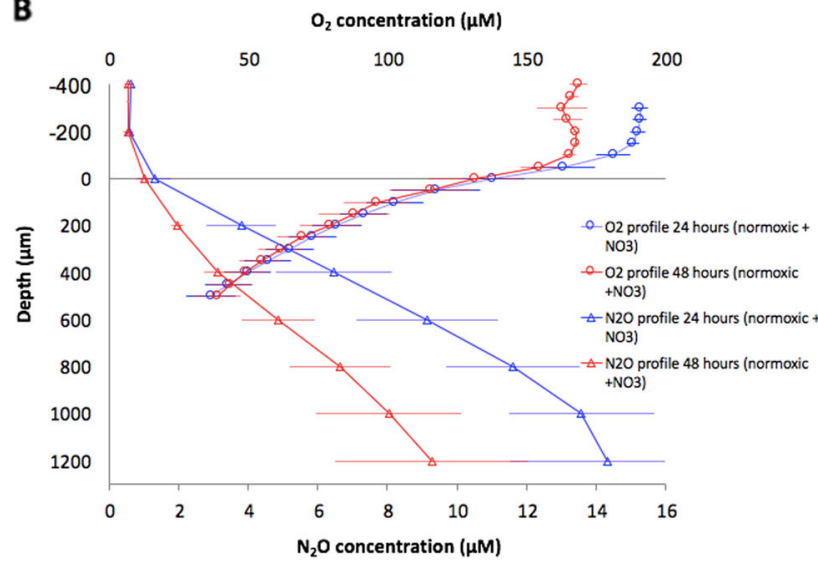

Fig. $5 \mathrm{O}_{2}$ and $\mathrm{N}_{2} \mathrm{O}$ profiles from alginate-encapsulated $P$. aeruginosa. a $P$. aeruginosa cultured under normoxic conditions (circles) and anoxic conditions with $10 \mathrm{mM} \mathrm{NO}_{3}{ }^{-}$(triangles). Furthermore, a control measurement of $\mathrm{N}_{2} \mathrm{O}$ on alginate-encapsulated $P$. aeruginosa grown without $\mathrm{NO}_{3}{ }^{-}$(asterisk). b $P$. aeruginosa cultured under normoxic conditions supplemented with $10 \mathrm{mM} \mathrm{NO}_{3}{ }^{-}$. $\mathrm{O}_{2}$ profiles (circles) and $\mathrm{N}_{2} \mathrm{O}$ profiles (triangles). Bars represent average \pm standard deviation from 3 to 4 replicates. All measurements were performed at $37^{\circ} \mathrm{C}$ in growth medium

\section{$\mathrm{O}_{2}$ imaging}

The incorporation of $\mathrm{O}_{2}$-sensitive nanoparticles in the alginate beads enabled visualisation of the $\mathrm{O}_{2}$ distribution relative to the bacterial aggregates. The $\mathrm{O}_{2}$ images revealed steep $\mathrm{O}_{2}$ gradients in the periphery of the beads (Fig. 7c) forming a heterogeneous landscape of $\mathrm{O}_{2}$ concentration within the $\mathrm{O}_{2}$ provisioned part of the beads that roughly followed the aggregate distribution, where aggregates exhibited complete $\mathrm{O}_{2}$ depletion and hypoxia in the surrounding alginate matrix. Atmospheric $\mathrm{O}_{2}$ saturation was only observed at the immediate bead surface.

\section{DISCUSSION}

Cultures of $P$. aeruginosa in alginate beads exhibit several characteristics of aggregated bacteria found in the lungs of CF patients and in chronic wounds, in regard to aggregate size, growth, $\mathrm{O}_{2}$ limitation, physiological heterogeneity, and antibiotic tolerance. ${ }^{14}$ This enabled our study of in vivo-like growth patterns and the chemical microenvironment of $P$. aeruginosa with and without electron acceptors via a variety of invasive and noninvasive methods. The most intense growth of $P$. aeruginosa was observed in the presence of the two electron acceptors $\mathrm{O}_{2}$ and $\mathrm{NO}_{3}{ }^{-}$, enabling both aerobic respiration and denitrification in the alginate beads, while complete absence of electron acceptors resulted in an arrested growth state.

We studied the growth patterns of $P$. aeruginosa in the presence and absence of $\mathrm{O}_{2}$ and $\mathrm{NO}_{3}{ }^{-}$at different spatial scales using OCT for mesoscopic and macroscopic scale, CLSM to unravel structures at a microscopic scale, and quantitative PNA-FISH for information on the growth potential. OCT has previously been used to study the formation and growth dynamics of biofilms in flow chambers and various carrier materials $\mathrm{s}^{4,44}$ and of clinical biofilms in nasal polyps, ${ }^{28}$ but to our knowledge OCT has not previously been used to investigate bacteria growing in alginate beads. The presence of bacteria increased local backscatter in the alginate matrix resulting in a stronger OCT signal. ${ }^{44}$ However, the alginate matrix also scattered light, and a quantification of bacterial growth thus relies on a clear separation of the OCT signals originating from the bacteria and the alginate. We found that bacterial growth led to an enhancement of the OCT signal relative to the alginate bead, but only within the first $200 \mu \mathrm{m}$ from the bead surface (see Supplementary Fig. S2). While OCT allows for a potential operational depth of view of several $\mathrm{mm}^{\prime} \mathrm{s},{ }^{45}$ the high density of bacteria in the outermost bead layers leads to intense multiple

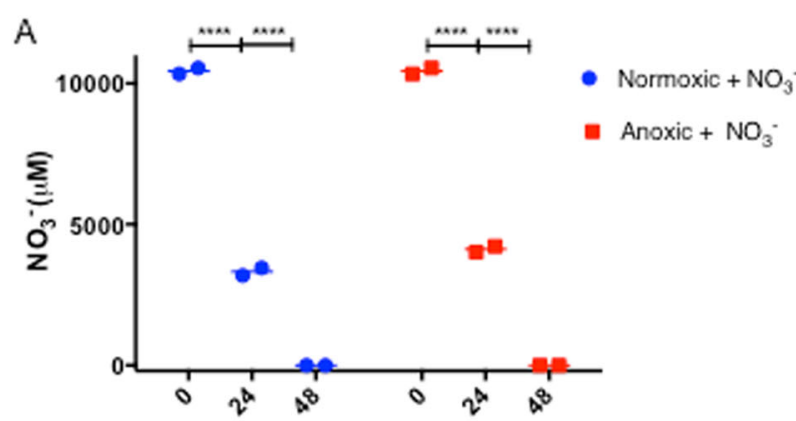

B
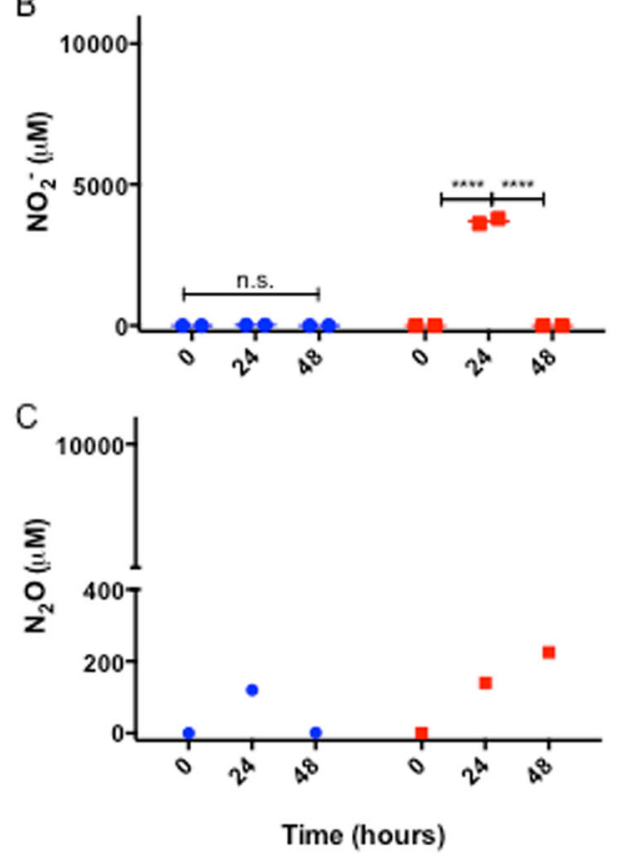

Fig. 6 Dynamics of a $\mathrm{NO}_{3}{ }^{-}$, b $\mathrm{NO}_{2}{ }^{-}$, and $\mathbf{c} \mathrm{N}_{2} \mathrm{O}(\mu \mathrm{M})$ in growth medium quantified by Griess colometric reaction and microsensor measurements directly in growth medium. $\mathrm{NO}_{3}{ }^{-}$and $\mathrm{NO}_{2}{ }^{-}$ measurements are based on duplicate sampling from medium (error bars too small to be visualised), and $\mathrm{N}_{2} \mathrm{O}$ concentration represents on a single measurement directly in medium. Significant differences as indicated. n.s. not significant; ${ }^{* * * *} p \leq 0.0001$ 

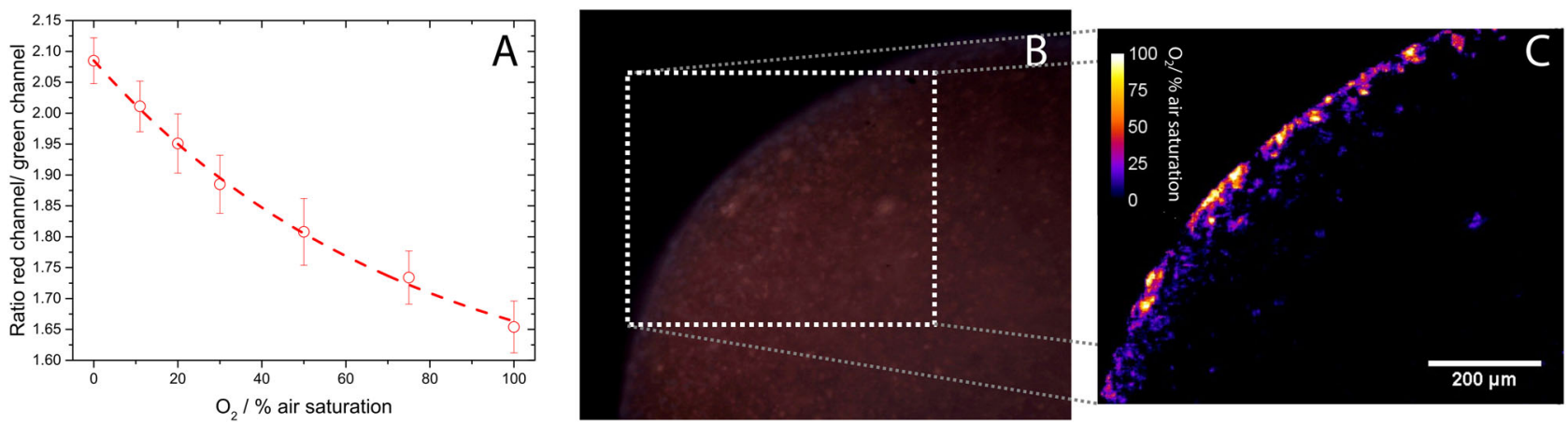

Fig. 7 Ratiometric imaging of $\mathrm{O}_{2}$ with oxygen-sensitive nanoparticles incorporated in alginate beads with $P$. aeruginosa. a Calibration of nanoparticles in alginate beads submerged in water of increasing $\mathrm{O}_{2}$ concentrations. The $\mathrm{O}_{2}$ was quantified as the ratio of the Red and Green channels extracted from RGB colour images obtained with a simple USB microscope. b Alginate bead with sensor nanoparticles, c zoom-in and visualisation of $\mathrm{O}_{2}$ distribution in alginate bead after $24 \mathrm{~h}$ of growth with P. aeruginosa. Size of bar: $200 \mu \mathrm{m}$

scattering of the NIR probing light causing a rapid vertical attenuation and thus loss of image contrast of the collected OCT signal ${ }^{46}$ resulting in an operational depth of view that was comparable to CLSM. ${ }^{47}$ Evidently, such application of OCT can be further optimised, e.g., by decreasing scatter in the alginate matrix using washed less optically opaque alginate, but such technical optimisation was beyond the scope of this study. Still, the OCT data in our study complemented higher-resolution microscopy techniques and provided a non-invasive macroscopic overview of the growth dynamics and growth zones in intact alginate beads. With OCT, it was thus possible to monitor the overall growth zone of $P$. aeruginosa in alginate beads (Fig. S1), while high-resolution CLSM enabled (i) visualisation and quantification of microcolony size and distribution in the alginate beads (Fig. 2) and (ii) local growth potential measurements when used in combination with a quantitative PNA-FISH protocol (Fig. 3).

Supplementing $P$. aeruginosa with two electron acceptors $\left(\mathrm{O}_{2}\right.$ and $\mathrm{NO}_{3}{ }^{-}$) resulted in higher growth potentials (Figs. 2, 3) at $24 \mathrm{~h}$ as compared to $48 \mathrm{~h}$ incubation. Moreover, a heterogeneous growth pattern of $P$. aeruginosa was observed in the alginate beads after $48 \mathrm{~h}$ incubation with larger aggregates situated near the oxygenated bead surface. Physiological heterogeneity within biofilms is largely driven by the activity and biomass distribution of the bacteria in combination with mass transfer limitation by diffusion of electron acceptors, substrate and products of bacterial metabolism in the biofilm matrix and in the diffusive boundary layer between the mixed water phase and the biofilm. ${ }^{11}$ Typically, bacterial depletion of $\mathrm{O}_{2}$ in the biofilm periphery limits diffusion to deeper parts, ${ }^{48}$ and we found that such development of $\mathrm{O}_{2}$ concentration gradients in the alginate beads lead to a heterogeneous growth pattern over time, where only the bacteria positioned near the bead surface had sufficient access to the preferred electron acceptor $\mathrm{O}_{2}$. While anoxic grown $P$. aeruginosa with access to $\mathrm{NO}_{3}{ }^{-}$displayed a very homogeneous growth pattern after $24 \mathrm{~h}$, these beads also showed signs of a heterogeneous growth pattern after $48 \mathrm{~h}$ (Fig. 2). This shift was probably due to depletion of bead-incorporated $\mathrm{NO}_{3}{ }^{-}$, where after $\mathrm{NO}_{3}{ }^{-}$ was only available by diffusion from the growth medium. These results are in accordance with previous studies showing a heterogeneous distribution of bacterial aggregate sizes, with significantly larger aggregates in the periphery as compared to deeper in the beads after $48 \mathrm{~h}$ in normoxic grown alginateencapsulated $P$. aeruginosa with and without $100 \mathrm{mM} \mathrm{NO}_{3}{ }^{-}$ supplement. ${ }^{14}$

The results from OCT and CLSM corresponded well with the quantitative PNA-FISH results in terms of showing increased growth depth in the presence of $\mathrm{NO}_{3}{ }^{-}$, while the availability of $\mathrm{O}_{2}$ did apparently not affect growth depth into the alginate beads. The latter finding confirms that $\mathrm{O}_{2}$ is strongly affected by diffusion limitation. ${ }^{49}$ In addition, quantitative PNA-FISH provided an estimate on the growth potential, expressed as fluorescence intensity, which has been shown to correlate with growth rate in $P$. aeruginosa. ${ }^{21}$ Contrary to growth depth, the growth potential was affected by the presence of $\mathrm{O}_{2}$, and we found a significantly higher growth potential with $\mathrm{O}_{2}$ at $24 \mathrm{~h}$ as compared to $48 \mathrm{~h}$. This suggests that the contribution of $\mathrm{O}_{2}$ to the overall growth may be limited after $48 \mathrm{~h}$, and that the preferred electron acceptor $\mathrm{O}_{2}$ initially facilitates a more intense growth burst than with $\mathrm{NO}_{3}{ }^{-}$, which correlates well with the low growth rate of $P$. aeruginosa observed in vivo in the mucus of chronically infected CF lungs. ${ }^{21}$ Furthermore, this is in accordance with a higher energy yield by $\mathrm{O}_{2}$ respiration as compared to denitrification. ${ }^{50,51}$ Cell counts further confirmed a more intense growth in the presence of both $\mathrm{O}_{2}$ and $\mathrm{NO}_{3}{ }^{-}$(Fig. 4).

Interestingly, bacterial growth in beads with no electron acceptors did not result in a decrease in CFU but rather lead to a steady state in cell counts throughout the study, which is in support of $P$. aeruginosa's remarkable ability for long-time survival. ${ }^{52}$ Previous studies have thus demonstrated that $P$. aeruginosa is capable of long-term anaerobic survival via fermentation of amino acids, ${ }^{52-54}$ which were present in the growth medium.

To gain further insight to factors governing the growth dynamics of $P$. aeruginosa in the beads as observed with OCT, CLSM, and quantitative PNA-FISH, we used microsensors to quantify chemical gradients in the alginate beads. Based on such measurements, we estimated oxic respiration from the net consumption of $\mathrm{O}_{2}$ and denitrification from the net production of $\mathrm{N}_{2} \mathrm{O}$ in the beads, respectively. The observed decline in $\mathrm{O}_{2}$ in the water just above the alginate bead surface showed the presence of a diffusive boundary layer around the bead, ${ }^{55}$ and microsensor measurements demonstrated the presence of steep $\mathrm{O}_{2}$ concentration gradients and thus high $\mathrm{O}_{2}$ consumption in beads incubated under normoxic conditions. However, the $\mathrm{O}_{2}$ uptake decreased with time (Fig. 5a) in line with our observation of a decreasing growth rate over time as determined by quantitative PNA-FISH (Fig. 3). This may indicate onset of substrate limitation for bacterial growth in the alginate beads.

Beads incubated in normoxic medium with $\mathrm{NO}_{3}{ }^{-}$showed steep $\mathrm{O}_{2}$ concentration gradients, but contrary to beads grown without $\mathrm{NO}_{3}{ }^{-}$, the $\mathrm{O}_{2}$ uptake did not decrease with time (Fig. 5b). However, such sustained high $\mathrm{O}_{2}$ consumption was not reflected in higher growth potentials, which showed a decrease between 24 and $48 \mathrm{~h}$ of incubation (Fig. 3a). Some bacteria can perform socalled aerobic denitrification during hypoxic conditions in the presence of $\mathrm{NO}_{3}{ }^{-}$. Initially described by Robertson and Kuenen, ${ }^{56}$ aerobic denitrification can explain how $\mathrm{NO}_{3}{ }^{-}$respiration may proceed in the presence of $\mathrm{O}_{2}{ }^{56}$ In $P$. aeruginosa this ability is 

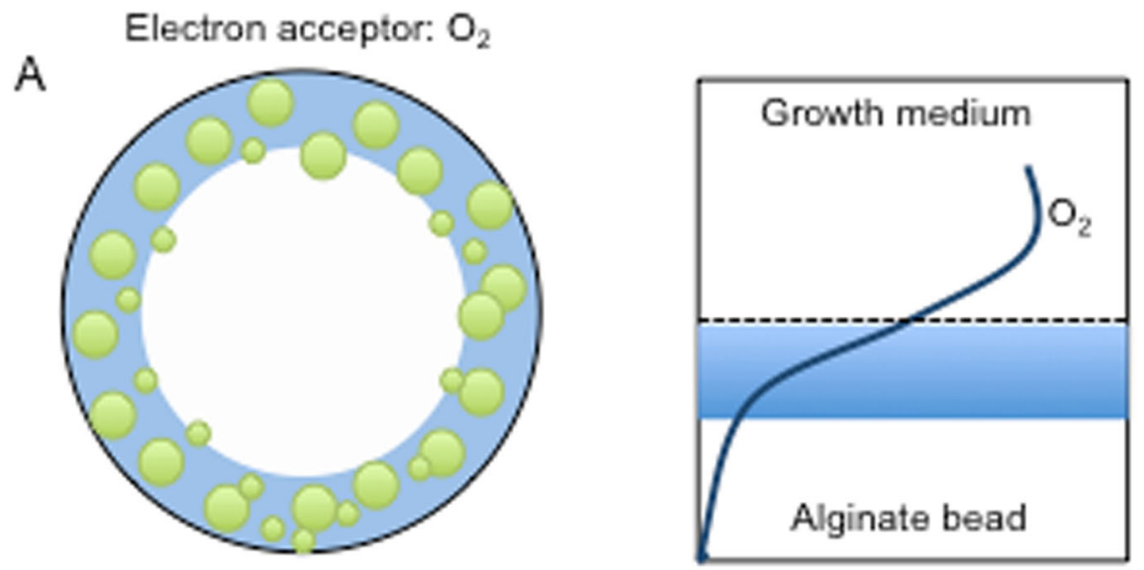

Electron acceptors: $\mathrm{O}_{2}$ and $\mathrm{NO}_{3}{ }^{-}$

B

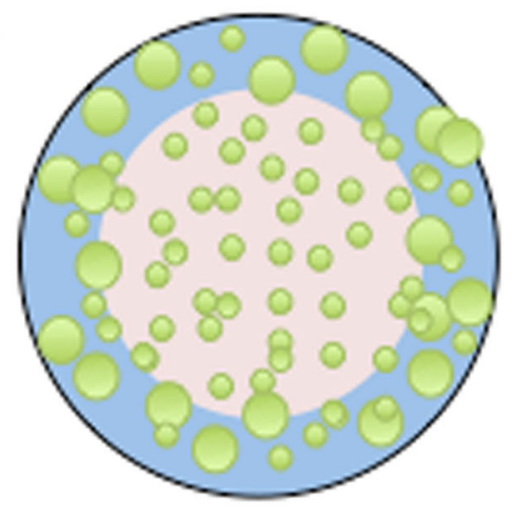

Electron acceptor: $\mathrm{NO}_{3}{ }^{-}$

C

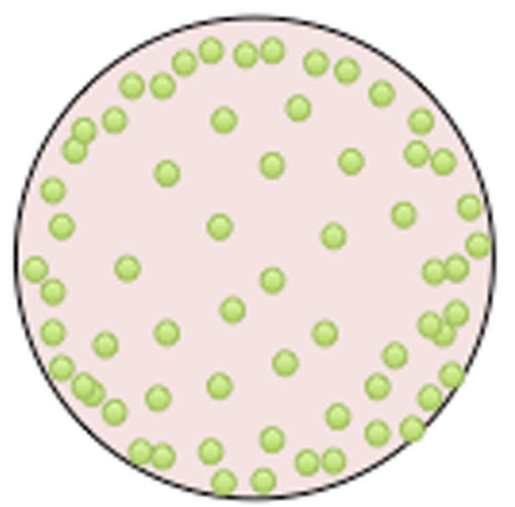

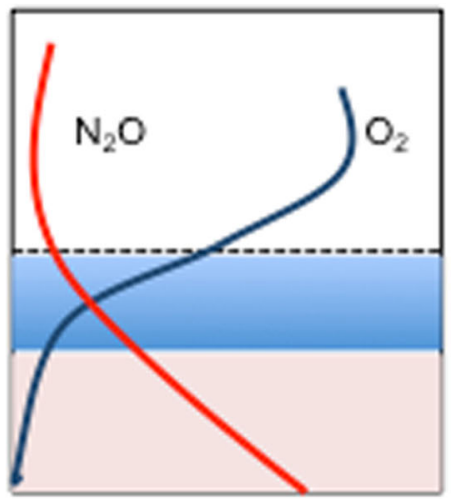

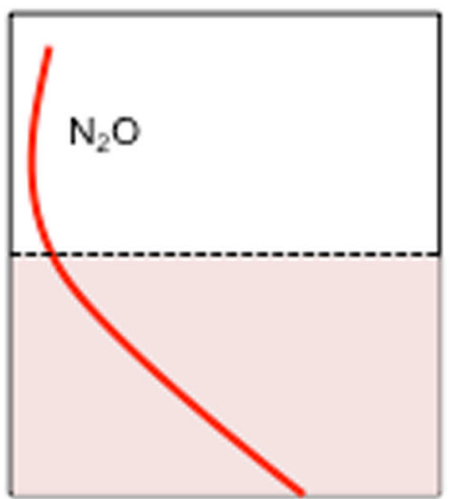

Fig. 8 Schematic presentation of growth dynamics and chemical dynamics in alginate beads under different growth conditions. a Normoxic growth, b normoxic growth with $\mathrm{NO}_{3}{ }^{-}$, and c anoxic growth with $\mathrm{NO}_{3}{ }^{-}$. Green circles represent aggregates of $P$. aeruginosa within the alginate bead. $\mathrm{O}_{2}$ : blue/light blue. $\mathrm{NO}_{3}{ }^{-}$: red/light red. Sizes not to scale

evidenced by the expression of overlapping gene sets depending on $\mathrm{O}_{2}$ concentration, where hypoxia triggers denitrification genes. ${ }^{57}$ Moreover, the ability to perform intra-aerobic respiration has been proposed, where $\mathrm{NO}_{3}{ }^{-}$is reduced to $\mathrm{NO}$, which is dismutated into $\mathrm{N}$ (nitrogen) and $\mathrm{O}_{2} \cdot{ }^{58}$ Such formed $\mathrm{O}_{2}$ would in theory proceed in the aerobic respiration chain, which would then support high $\mathrm{O}_{2}$ consumption rates. However, we note that the presence of aerobic denitrification or intra-aerobic respiration remains to be demonstrated in $P$. aeruginosa. Maximal $\mathrm{N}_{2} \mathrm{O}$ concentration was detected in the hypoxic zone of the alginate beads, indicating that denitrification mainly occurred here (Fig. 5). Production of $\mathrm{N}_{2} \mathrm{O}$ decreased with time (Fig. 5b), which may reflect $\mathrm{NO}_{3}{ }^{-}$depletion in the beads and the surrounding medium.
This was supported by the complete exhaustion of $\mathrm{NO}_{3}{ }^{-}$after $48 \mathrm{~h}$ (Fig. 6a).

In beads incubated in anoxic medium with $\mathrm{NO}_{3}{ }^{-}, P$. aeruginosa solely relied on denitrification for anaerobic respiration as indicated by the observed $\mathrm{N}_{2} \mathrm{O}$ production, which decreased over time (Fig. 5b), leading to the appearance of a more heterogeneous size distribution of bacterial aggregates in the beads (Fig. 2) resembling the growth pattern observed in normoxic beads. As $\mathrm{N}_{2} \mathrm{O}$ is a key intermediate in the denitrification metabolic pathway, ${ }^{36}$ a decreasing $\mathrm{N}_{2} \mathrm{O}$ flux could indicate the onset of $\mathrm{NO}_{3}{ }^{-}$limitation within the beads after $48 \mathrm{~h}$ of growth, which was supported by our finding of complete consumption of $\mathrm{NO}_{3}{ }^{-}$after $48 \mathrm{~h}$ (Fig. 6a). We also followed the fate of $\mathrm{NO}_{2}{ }^{-}$in the growth 
medium (Fig. 6b), which showed a peak in $\mathrm{NO}_{2}{ }^{-}$for anoxic grown beads after $24 \mathrm{~h}$, and complete depletion after $48 \mathrm{~h}$. In normoxic incubations (with $\mathrm{NO}_{3}{ }^{-}$), no increase in $\mathrm{NO}_{2}{ }^{-}$was observed, but we speculate that such a peak may have occurred before the $24 \mathrm{~h}$ measurement, as $\mathrm{NO}_{3}{ }^{-}$in the presence of $\mathrm{O}_{2}$ was shown to facilitate a more intense growth initially. The $\mathrm{N}_{2} \mathrm{O}$ measurements in the growth medium showed that $\mathrm{N}_{2} \mathrm{O}$ accumulated to very high levels in the sealed system after $48 \mathrm{~h}$ (Fig. $6 \mathrm{c}$ ) further supporting a strong $\mathrm{NO}_{3}{ }^{-}$consumption during the incubations.

While our microsensor measurements revealed insight to the overall dynamics of $\mathrm{O}_{2}$ and $\mathrm{N}_{2} \mathrm{O}$ gradients in the alginate beads when incubated under different electron acceptor availability, we note that such measurements cannot provide detailed insight to the heterogeneous chemical landscape of individual microcolonies in the alginate beads. In a first attempt to link microcolony heterogeneity to the distribution in $\mathrm{O}_{2}$, we used ratiometric $\mathrm{O}_{2}$ imaging in a $24 \mathrm{~h}$ old alginate bead supplemented with $\mathrm{O}_{2}$ sensitive nanoparticles and grown under normoxic conditions (Fig. 7c). Ratiometric $\mathrm{O}_{2}$ imaging showed pronounced local variation in the outermost $100 \mu \mathrm{m}$ of the alginate bead. However, the used camera system for $\mathrm{O}_{2}$ imaging did not have enough spatial resolution to investigate co-localisation and enable correlations between microcolony size and $\mathrm{O}_{2}$ distribution. However, such combined biomass and $\mathrm{O}_{2}$ imaging $^{34}$ in the alginate beads has $\mathrm{a}$ strong potential to further resolve links between the chemical microenvironment and growth of $P$. aeruginosa in the alginate bead. Such approach would require more measurements of $\mathrm{O}_{2}$ distribution with nanoparticles in the beads using higherresolution microscopic imaging. ${ }^{33,59}$

In conclusion, growth in alginate beads represents a useful in vitro model for the in vivo growth of $P$. aeruginosa in chronic infections. This model system is suitable for testing responses in bacterial metabolism and growth patterns to the availability of different electron acceptors and donors during chronic infections, and the effect of the different treatments are summarised in Fig. 8. The alginate bead model may also prove very suitable for testing antimicrobial susceptibility and tolerance of $P$. aeruginos $a$ and other pathogens involved in mono-species and multi-species infections. It is well known that $\mathrm{O}_{2}$ limitation contributes to antibiotic tolerance of bacteria in biofilms, ${ }^{22}$ but addition of electron acceptors such as $\mathrm{NO}_{3}{ }^{-}$and $\mathrm{O}_{2}$ may antagonise this effect and enhance the susceptibility towards antibiotics. ${ }^{60,61}$

\section{METHODS}

\section{Bacterial strains}

A wild-type $P$. aeruginosa strain PAO1 was obtained from the Pseudomonas Genetic Stock Center (http://www.pseudomonas.med.ecu.edu). To enable visualisation of PAO1 cells, GFP constitutively expressed on plasmid pMRP9 $^{62}$ was used.

\section{Growth conditions}

Cultures were propagated from $-80^{\circ} \mathrm{C}$ freeze culture stocks and grown overnight (ON) in lysogeny broth (LB) for approximately $18 \mathrm{~h}$ at $37^{\circ} \mathrm{C}$ under continuous shaking at 180 RPM. Subsequently, the LB ON culture was used for inoculation in low nutritional R2A broth (Lab M Limited, UK) supplemented with $0.05 \mathrm{M}$ Tris- $\mathrm{HCl}$ buffer $(\mathrm{pH} 7.6)$ and $0.5 \%$ glucose (abbreviated R2A), and left to acclimatise ON until further use. The medium to volume ratio was $1: 2.5$.

\section{Bead preparation}

Alginate beads of $2.4 \mathrm{~mm} \pm 0.1 \mathrm{~mm}$ in diameter (mean \pm standard deviation) were prepared by a previously described method, ${ }^{14}$ with the exception of adding $10 \mathrm{mM}$ potassium nitrate $\left(\mathrm{KNO}_{3}{ }^{-}\right)$(P8394, SigmaAldrich, USA) to some of the beads. In all experiments, beads were incubated in R2A medium (with or without $10 \mathrm{mM} \mathrm{KNO}_{3}{ }^{-}$) at $100 \mathrm{RPM}$ at $37^{\circ} \mathrm{C}$ for 24 or $48 \mathrm{~h}$, respectively. For normoxic conditions, culture flasks were sealed with cotton. To achieve anoxic growth conditions, the medium was flushed with nitrogen gas $\left(\mathrm{N}_{2}\right)$ for $5 \mathrm{~min}$, where after the culture flask was immediately sealed airtight.

The bacterial growth of $P$. aeruginosa in the alginate beads was studied after 24 and $48 \mathrm{~h}$ in response to four permutations of the growth conditions: (i) Normoxic culture without $\mathrm{NO}_{3}{ }^{-}$, (ii) normoxic culture with $\mathrm{NO}_{3}{ }^{-}$, (iii) anoxic culture without $\mathrm{NO}_{3}{ }^{-}$, and (iv) anoxic culture with $\mathrm{NO}_{3}{ }^{-}$. Separate culture flasks were prepared for each time point, but all cultures originated from the same two batches of alginate beads (with and without $\mathrm{NO}_{3}{ }^{-}$) inoculated with the same PAO1 ON culture.

\section{Optical coherence tomography}

We used a commercially available spectral-domain OCT system (Ganymede II, Thorlabs $\mathrm{GmbH}$, Germany) equipped with an objective lens with an effective focal length of $36 \mathrm{~mm}$, and a working distance of $25.1 \mathrm{~mm}$ (LSM03; Thorlabs GmbH, Germany). The operating principle and components of the OCT system are described in detail elsewhere ${ }^{63,64}$ and in Supplementary. In order to use the OCT signal to compare bacterial growth between experimental treatments, OCT measurements were performed under well-defined optical conditions in terms of OCT system settings. A single alginate bead was placed in a black screw cap filled with $800 \mu \mathrm{L}$ of distilled water. Using $z$-axis OCT scans (so-called A-scans), the image was brought into focus via the manual focusing stage and by adjusting the reference light intensity as well as the position of the reference length. ${ }^{64}$ After optimisation of image acquisition settings, the configuration was not changed, and subsequent measurements on alginate beads were performed under identical conditions. Each alginate bead was first scanned at high resolution in three (technical) replicate cross-sectional scans (so-called B-scans) followed by one full 3D scan (so-called C-scan) and rendering of the entire bead. OCT imaging was done in (biological) triplicates for each treatment after 24 and $48 \mathrm{~h}$ of incubation, respectively.

Visualisation of OCT B-scan and C-scan was done with the manufacturers imaging software (Thorlmage 4.2; Thorlabs $\mathrm{GmbH}$, Germany) using the built-in brightness and contrast functions. The images were visualised assuming a constant refractive index of water $(n=1.33)$. The attenuation of the A-scan signal can be used to understand changes in the structure of the alginate bead. We extracted three vertical A-scans from the B-scans over the area surrounding the highest point of the alginate bead (Fig. S1). OCT images were extracted in B-scan mode with manually optimised brightness and contrast adjustment and assuming a refractive index of 1.33 (for water). These adjustments separated the background noise from the OCT signal generated from the alginate beads.

\section{Microscopy}

A confocal laser scanning microscope (Zeiss Imager.Z2, LSM710 CLSM; Zeiss) operated with the manufacturers software (Zen2010, version 6.0; Zeiss, Germany) was used for imaging alginate-encapsulated, GFP-tagged PAO1. Samples were prepared by cutting the beads in half with a sterile scalpel. Cut beads were mounted in the dents of a flow-cell with the cut surface facing upwards. $10 \mu \mathrm{L}$ millie water was applied to the cut bead surface, and a cover glass was fixed to the flow-cell with silicone sealant, making sure the cut surface was in close contact with the cover glass. The flow-cell was mounted on the microscope, and images were taken from the cut surface of the bead enabling visualisation of the distribution of bacterial aggregates from the periphery of the beads and towards the bead interior. Imaging of GFP-tagged $P$. aeruginosa was done with a 40X/ NA1.3 oil objective, using laser excitation at $488 \mathrm{~nm}$, and an emission filter range from 495 to $605 \mathrm{~nm}$ with a peak at $510 \mathrm{~nm}$. The resulting images were processed with Imaris image processing software (v8.3.1; Bitplane, Switzerland).

\section{Microscopy combined with quantitative PNA-FISH}

Alginate beads from the four permutations, sampled after 24 and $48 \mathrm{~h}$, were stored for at least $24 \mathrm{~h}$ in $4 \%$ formaldehyde (Hounisen, Denmark) kept at $4{ }^{\circ} \mathrm{C}$ and supplemented with $0.25 \mathrm{CaCl}_{2}$ for stabilisation. Subsequently, the beads were embedded in paraffin, cut in $4-\mu \mathrm{m}$ thick sections with a standard microtome, fixed on cover slides and kept dark at $4{ }^{\circ} \mathrm{C}$ until further use; we note that this procedure did not work with the anoxic beads incubated without $\mathrm{NO}_{3}{ }^{-}$due to bead disruption. Staining of bead sections was conducted with a Texas Red-conjugated PNA-FISH probe specific for $P$. aeruginosa $16 \mathrm{~S}$ rRNA (AdvanDx, USA) by previously described methods. ${ }^{14,21} \mathrm{~A}$ microscope slide with the fixated and PNA-FISH stained 4- $\mu \mathrm{m}$ sections of alginate beads was mounted on the microscope. Imaging of the alginate bead sections for quantitative PNA-FISH was done 
with identical image acquisition settings for all pictures: Fluorescence images were recorded as 1- $\mu \mathrm{m}$ step size $z$-stacks at an image resolution of $4096 \times 4096$ pixels, with an averaging of two scans, and 16-bit colour depth using a $63 \times / 1.4 \mathrm{NA}$ oil immersion objective, laser excitation at 594 $\mathrm{nm}$, and emission range from 600 to $695 \mathrm{~nm}$ with a peak of $615 \mathrm{~nm}$. Quantification of microcolony fluorescence (mean intensity) was performed using Imaris image processing software (v8.3.1; Bitplane, Switzerland). Image thresholding was applied, which discriminated background and foreground fluorescence with the use of the Measuring Pro expansion pack for the Imaris software (Bitplane, Switzerland). A minimum colony size was set to $10 \mu^{3}$ to avoid inclusion of planktonic bacteria in the analysis of bacterial aggregates. ${ }^{14}$ The mean fluorescence intensity of each micro colony was measured on a 16-bit scale from 0-65535 fluorescence intensity units (FU). Kragh et al. ${ }^{21}$ previously described a linear correlation between growth rate and fluorescence intensity of PNA-FISH stained rRNA molecules in $P$. aeruginosa. Based on this relationship, the fluorescence intensity of PNA-FISH stained samples could be used as a proxy for apparent growth rate. Colony distance from the discernible periphery of alginate beads was measured manually for individual colonies using the measuring tool in the Imaris software (Bitplane, Switzerland) and was plotted against fluorescence intensity.

\section{Colony-forming units}

For quantification of CFU, beads were dissolved using a solution of $\mathrm{Na}_{2} \mathrm{CO}_{3}$ $(0.05 \mathrm{M})$ and citric acid $(0.02 \mathrm{M}){ }^{65}$ The dissolved bead slurry was serially diluted before plating on LB plates for enumeration of cells via colony formation. CFUs were determined in biological triplicates.

\section{Microsensor measurements}

Beads were submerged in a Petri dish filled with pre-warmed R2A medium (with or without $\mathrm{NO}_{3}{ }^{-}$) that was kept at $37^{\circ} \mathrm{C}$ under gentle ventilation by a fine air or nitrogen stream directed towards the surface via a Pasteur pipette connected to an air pump or $\mathrm{N}_{2}$ gas cylinder. Profiles of $\mathrm{O}_{2}$ concentration vs. depth in the alginate bead were measured with an amperometric $\mathrm{O}_{2}$ microsensor ( $25 \mu \mathrm{m}$ tip diameter; OX25, Unisense A/S, Denmark) mounted on a motorised micromanipulator (MU1 Pyro-Science $\mathrm{GmbH}$, Germany). Similarly, $\mathrm{N}_{2} \mathrm{O}$ concentration profiles were measured with an $\mathrm{O}_{2}$-insensitive amperometric $\mathrm{N}_{2} \mathrm{O}$ microsensor ( $25 \mu \mathrm{m}$ tip diameter; $\mathrm{N} 2 \mathrm{O} 25$, Unisense A/S, Denmark). All measurements were performed in 3-4 biological replicates. Both microsensors were connected to a pA metre (Unisense A/S, Denamark) that was interfaced to a PC via an A/D converter (Profix; Pyroscience $\mathrm{GmbH}$, Germany). Linear calibrations of the microsensors were performed as specified by the manufacturer via measurements with the $\mathrm{O}_{2}$ microsensor in air saturated and $\mathrm{O}_{2}$-free water, and measurements with the $\mathrm{N}_{2} \mathrm{O}$ microsensor in $\mathrm{N}_{2} \mathrm{O}$-free water, followed by measurement upon addition of defined aliquots of $\mathrm{N}_{2} \mathrm{O}$ saturated water.

Concentration profiles were recorded in beads incubated for 24 and $48 \mathrm{~h}$ after encapsulation of $P$. aeruginosa in alginate, respectively. The position, where the microsensor tip touched the bead surface (depth $=0$ ), was determined visually with the aid of a USB microscope (model AM7515MZTL, dino-lite.eu) aiming after the centre of the uppermost bead surface. Profile measurements were conducted in steps of 50 or $200 \mu \mathrm{m}$ through the bead. Microsensor positioning and data acquisition were done with dedicated profiling software (Profix; Pyro-Science GmbH, Germany).

To assess $\mathrm{N}_{2} \mathrm{O}$ concentration directly in the growth medium, the sensor tip was submerged in the growth medium and the resulting concentration was recorded as quickly as possible after removal of the cotton or rubber sealing.

\section{Calculations of $\mathrm{O}_{2}$ and $\mathrm{N}_{2} \mathrm{O}$ flux}

Net production of $\mathrm{N}_{2} \mathrm{O}$ and net consumption of $\mathrm{O}_{2}$ in the alginate beads were estimated as gas fluxes from measured steady-state concentration profiles, by a modified version of Fick's first law of diffusion, ${ }^{66}$ where the slope of the profile in the alginate bead was calculated from three consecutive measurements, from the upper quasi-linear parts of the profiles: ${ }^{39}$

$J=0.5\left[-D \frac{C_{\mathrm{a}}-C_{\mathrm{b}}}{X_{\mathrm{a}}-X_{\mathrm{b}}}\right]+0.5\left[-D \frac{C_{\mathrm{b}}-C_{\mathrm{c}}}{X_{\mathrm{b}}-X_{\mathrm{c}}}\right]$,

where $J$ is the flux of $\mathrm{O}_{2}$ or $\mathrm{N}_{2} \mathrm{O}\left(\mathrm{nmol} \mathrm{cm}{ }^{-2} \mathrm{~min}^{-1}\right), D$ is the molecular diffusion coefficient of $\mathrm{O}_{2}\left(1.5 \times 10^{-5} \mathrm{~cm}^{2} \mathrm{~s}^{-1}\right)^{55}$ or $\mathrm{N}_{2} \mathrm{O}\left(2.76 \times 10^{-5} \mathrm{~cm}^{2}\right.$ $\left.\mathrm{s}^{-1}\right)^{67}$ in water at $37^{\circ} \mathrm{C}$, and $\mathrm{C}$ is the concentration of $\mathrm{O}_{2}$ or $\mathrm{N}_{2} \mathrm{O}\left(\mu \mathrm{mol} \mathrm{L}{ }^{-1}\right)$ at depth $x_{n}(\mu \mathrm{m})$, where $n=\mathrm{a}, \mathrm{b}$ or $\mathrm{c}$ denotes three subsequent measurements at increasing depth (Eq. 1).

$\mathrm{NO}_{3}{ }^{-}$and $\mathrm{NO}_{2}{ }^{-}$quantification

The $\mathrm{NO}_{3}{ }^{-}$and $\mathrm{NO}_{2}{ }^{-}$concentration in fresh and spent $\mathrm{NO}_{3}{ }^{-}$-supplemented R2A medium during the time course of the experiments was quantified by the Griess colorimetric reaction (no. 780001, Cayman Chemicals, USA), in technical duplicates, as previously described. ${ }^{39}$

Imaging of $\mathrm{O}_{2}$

In order to image the $\mathrm{O}_{2}$ distribution within alginate beads harbouring $P$. aeruginosa, $\mathrm{O}_{2}$-sensitive sensor nanoparticles were incorporated into the beads. The sensor nanoparticles contained an $\mathrm{O}_{2}$-sensitive indicator (PtTFPP) and an insensitive reference dye (MY) and were prepared as described elsewhere. ${ }^{33,68}$ The sensor nanoparticles were added to the alginate-bacterial solution prior to bead preparation (sensor particle to alginate ratio: 1:50 vol/vol). After $24 \mathrm{~h}$ of growth, ratiometric $\mathrm{O}_{2}$ imaging of the bead was performed as described below.

For imaging, a bead was cut in half and placed on a cover glass with the cut surface facing the glass surface. The cut bead was covered with fresh medium and left to acclimate for a few minutes. A USB RGB microscope with built-in UV ( $405 \mathrm{~nm}$ ) LED illumination (model AM4113-FVT, dino-lite. eu) was placed below the cover glass and was used to obtain images of the cut bead surface. After image acquisition, the obtained RGB images were split into the three colour channels (red, green, and blue) using the free image analysis software ImageJ (imagej.net). As the $\mathrm{O}_{2}$-sensitive indicator emits in the red channel and the reference indicator in the green channel, the ratio between these two channels could be used to obtain an $\mathrm{O}_{2}$ image. Ratios were calculated using the plugin Ratio Plus (https://imagej. nih.gov/ij/plugins/ratio-plus.html) and were linked to $\mathrm{O}_{2}$ concentration by a previously obtained calibration using the curve fitting function of ImageJ. For the calibration, alginate beads with sensor nanoparticles but without bacteria were submerged and imaged in water containing known $\mathrm{O}_{2}$ levels. The $\mathrm{O}_{2}$ levels were adjusted by flushing the water with an air/ $\mathrm{N}_{2}$ mixture using a PC-controlled gas mixer (Sensorsense, The Netherlands). Detailed additional information on ratiometric $\mathrm{O}_{2}$ imaging using sensor nanoparticles can be found in recent publications. ${ }^{32,33,68}$

\section{Statistics}

Data were analysed for statistical significance with SPSS version 24 (IBM, USA) and GraphPad Prism version 6 (GraphPad Software, USA). Data were illustrated with GraphPad Prism. Group comparisons for quantitative PNAFISH data (Fig. 3) were made using either Mann-Whitney $U$ test (for growth depth calculated as IQR) or independent samples $t$-test on log transformed values (apparent growth rate, expressed as mean fluorescence intensity). Log growth rate and depth were correlated using Pearson correlation. Flux rates (Fig. 5) were compared by Mann-Whitney $U$ test. Changes in CFU (Fig. 4), concentrations of $\mathrm{NO}_{3}{ }^{-}$and $\mathrm{NO}_{2}{ }^{-}$(Fig. 6), as well as differences in OCT dB signal over time (Fig. 1) were analysed by two-way ANOVA. Based on our experience with the effect of treatment and the standard deviation of the methods rarely exceeding $40 \%$ of the effect we expect that three replicates will allow us to detect significant differences with $p<0.05$ and a power of 0.80 . A two-sided $a$ of 0.05 was considered significant.

\section{ACKNOWLEDGEMENTS}

We thank Heidi Marie Paulsen for cutting alginate beads for the quantitative PNAFISH analysis. The project was supported by grants from the Danish Research Council/Natural Sciences (Sapere Aude Advanced grant to M.K.), the Danish Research Council/Technical and Production Sciences (M.Kü., P.Ø.J.), the Carlsberg Foundation (M.Kü., D.W.), and the Lundbeck Foundation (to T.B.).

\section{AUTHOR CONTRIBUTIONS}

M.S., M.Kü., K.K., and T.B. conceptualised the study, M.S. and M.Kü. wrote the main manuscript text, K.K. performed data acquisition for Figs. 5 and 7 and prepared Fig. 7, D.W. performed OCT data acquisition and analysis (Fig. 1, and Supplementary Figs. S1, S2), K.N.K. analysed data for Fig. 3, P.Ø.J. analysed the results and revised the manuscript, M.Ko. assisted with data collection for Fig. 6. All authors reviewed the manuscript. 


\section{ADDITIONAL INFORMATION}

Supplementary information accompanies the paper on the npj Biofilms and Microbiomes website (https://doi.org/10.1038/s41522-018-0047-4).

Competing interests: The authors declare no competing interests.

Publisher's note: Springer Nature remains neutral with regard to jurisdictional claims in published maps and institutional affiliations.

\section{REFERENCES}

1. Stewart, P. S. Mechanisms of antibiotic resistance in bacterial biofilms. Int. J. Med. Microbiol. 292, 107-113 (2002).

2. Costerton, J. W., Stewart, P. S. \& Greenberg, E. P. Bacterial biofilms: a common cause of persistent infections. Science 284, 1318-1322 (1999).

3. Hall-Stoodley, L. \& Stoodley, P. Evolving concepts in biofilm infections. Cell Microbiol. 11, 1034-1043 (2009).

4. Bjarnsholt, T. et al. The in vivo biofilm. Trends Microbiol. 21, 466-474 (2013).

5. Kirketerp-Moller, K. et al. Distribution, organization, and ecology of bacteria in chronic wounds. J. Clin. Microbiol. 46, 2717-2722 (2008).

6. Flemming, H. C., Neu, T. R. \& Wozniak, D. J. The EPS matrix: the "house of biofilm cells". J. Bacteriol. 189, 7945-7947 (2007).

7. Flemming, H. C. \& Wingender, J. The biofilm matrix. Nat. Rev. Microbiol. 8, 623-633 (2010).

8. Mayer, C. et al. The role of intermolecular interactions: studies on model systems for bacterial biofilms. Int. J. Biol. Macromol. 26, 3-16 (1999).

9. Burmolle, M. et al. Biofilms in chronic infections-a matter of opportunitymonospecies biofilms in multispecies infections. FEMS Immunol. Med. Microbiol. 59, 324-336 (2010).

10. Pabst, B., Pitts, B., Lauchnor, E. \& Stewart, P. S. Gel-entrapped Staphylococcus aureus bacteria as models of biofilm infection exhibit growth in dense aggregates, oxygen limitation, antibiotic tolerance, and heterogeneous gene expression. Antimicrob. Agents Chemother. 60, 6294-6301 (2016).

11. Stewart, P. S. \& Franklin, M. J. Physiological heterogeneity in biofilms. Nat. Rev. Microbiol. 6, 199-210 (2008)

12. Walters, M. C., Roe, F., Bugnicourt, A., Franklin, M. J. \& Stewart, P. S. Contributions of antibiotic penetration, oxygen limitation, and low metabolic activity to tolerance of Pseudomonas aeruginosa biofilms to ciprofloxacin and tobramycin. Antimicrob. Agents Chemother. 47, 317-323 (2003).

13. James, G. A. et al. Microsensor and transcriptomic signatures of oxygen depletion in biofilms associated with chronic wounds. Wound Repair Regen. 24, 373-383 (2016).

14. Sønderholm, M. et al. Pseudomonas aeruginosa aggregate formation in an alginate bead model system exhibits in vivo-like characteristics. Appl. Environ. Microbiol. 83, https://doi.org/10.1128/AEM.00113-17 (2017).

15. Cowley, E.S., Kopf, S.H., LaRiviere, A., Ziebis, W. \& Newman, D.K. Pediatric cystic fibrosis sputum can be chemically dynamic, anoxic, and extremely reduced due to hydrogen sulfide formation. Mbio 6, https://doi.org/10.1128/mBio.00767-15 (2015).

16. Hassett, D. J. et al. Pseudomonas aeruginosa hypoxic or anaerobic biofilm infections within cystic fibrosis airways. Trends Microbiol. 17, 130-138 (2009).

17. Worlitzsch, D. et al. Effects of reduced mucus oxygen concentration in airway Pseudomonas infections of cystic fibrosis patients. J. Clin. Invest. 109, 317-325 (2002).

18. Bjarnsholt, T. et al. Pseudomonas aeruginosa biofilms in the respiratory tract of cystic fibrosis patients. Pediatr. Pulm. 44, 547-558 (2009).

19. Jensen, P. O., Kolpen, M., Kragh, K. N. \& Kühl, M. Microenvironmental characteristics and physiology of biofilms in chronic infections of CF patients are strongly affected by the host immune response. Acta Pathol. Microbiol. Immunol. Scand. 125, 276-288 (2017).

20. Kolpen, M. et al. Polymorphonuclear leucocytes consume oxygen in sputum from chronic Pseudomonas aeruginosa pneumonia in cystic fibrosis. Thorax 65, 57-62 (2010).

21. Kragh, K. N. et al. Polymorphonuclear leukocytes restrict growth of Pseudomonas aeruginosa in the lungs of cystic fibrosis patients. Infect. Immun. 82, 4477-4486 (2014).

22. Borriello, G. et al. Oxygen limitation contributes to antibiotic tolerance of Pseudomonas aeruginosa in biofilms. Antimicrob. Agents Chemother. 48, 2659-2664 (2004).

23. Bjarnsholt, T., Tolker-Nielsen, T., Givskov, M., Janssen, M. \& Christensen, L. H. Detection of bacteria by fluorescence in situ hybridization in culture-negative soft tissue filler lesions. Dermatol. Surg. 35, 1620-1624 (2009).

24. Perry-O'Keefe, H. et al.Identification of indicator microorganisms using a standardized PNA FISH method. J. Microbiol. Methods 47, 281-292 (2001).
25. Wagner, M. \& Horn, H. Optical coherence tomography in biofilm research: a comprehensive review. Biotechnol. Bioeng. 9999, https://doi.org/10.1002/ bit.26283 (2017).

26. Blauert, F., Horn, H. \& Wagner, M. Time-resolved biofilm deformation measurements using optical coherence tomography. Biotechnol. Bioeng. 112, 1893-1905 (2015).

27. Haisch, C. \& Niessner, R. Visualisation of transient processes in biofilms by optical coherence tomography. Water Res. 41, 2467-2472 (2007).

28. Toth, L. et al. Optical coherence tomography for biofilm detection in chronic rhinosinusitis with nasal polyposis. Eur. Arch. Otorhinolaryngol. 270, 555-563 (2013).

29. Andersen, K., Kjaer, T. \& Revsbech, N. P. An oxygen insensitive microsensor for nitrous oxide. Sens. Actuators B Chem. 81, 42-48 (2001).

30. Revsbech, N. P. Analysis of microbial communities with electrochemical microsensors and microscale biosensors. Methods Enzymol. 397, 147-166 (2005).

31. Moßhammer, M. et al. Design and application of an optical sensor for simultaneous imaging of $\mathrm{pH}$ and dissolved $\mathrm{O}_{2}$ with low cross-talk. ACS Sensors. 6, 681-687 (2016)

32. Koren, K., Jakobsen, S. L. \& Kühl, M. In-vivo imaging of $\mathrm{O}_{2}$ dynamics on coral surfaces spray-painted with sensor nanoparticles. Sens. Actuators B Chem. 237, 1095-1101 (2016).

33. Koren, K., Brodersen, K. E., Jakobsen, S. L. \& Kühl, M. Optical sensor nanoparticles in artificial sediments-a new tool to visualize $\mathrm{O}_{2}$ dynamics around the rhizome and roots of seagrasses. Environ. Sci. Technol. 49, 2286-2292 (2015).

34. Kühl, M., Rickelt, L. F. \& Thar, R. Combined imaging of bacteria and oxygen in biofilms. Appl. Environ. Microbiol. 73, 6289-6295 (2007).

35. Pamp, S. J., Sternberg, C. \& Tolker-Nielsen, T. Insight into the microbial multicellular lifestyle via flow-cell technology and confocal microscopy. Cytom. Part $A$ 75, 90-103 (2009)

36. Zumft, W. G. Cell biology and molecular basis of denitrification. Microbiol. Mol. Biol. Rev. 61, 533-616 (1997).

37. Hassett, D. J. et al. Anaerobic metabolism and quorum sensing by Pseudomonas aeruginosa biofilms in chronically infected cystic fibrosis airways: rethinking antibiotic treatment strategies and drug targets. Adv. Drug Deliv. Rev. 54, 1425-1443 (2002).

38. Thauer, R. K., Jungermann, K. \& Decker, K. Energy conservation in chemotrophic anaerobic bacteria. Bacteriol. Rev. 41, 100-180 (1977).

39. Kolpen, M. et al. Nitrous oxide production in sputum from cystic fibrosis patients with chronic Pseudomonas aeruginosa lung infection. PLoS ONE 9, e84353 (2014).

40. Line, L. et al. Physiological levels of nitrate support anoxic growth by denitrification of Pseudomonas aeruginosa at growth rates reported in cystic fibrosis lungs and sputum. Front. Microbiol. 5, 1-11 (2014).

41. Grasemann, H. et al. Nitric oxide metabolites in cystic fibrosis lung disease. Arch. Dis. Child. 78, 49-53 (1998).

42. Palmer, K. L., Mashburn, L. M., Singh, P. K. \& Whiteley, M. Cystic fibrosis sputum supports growth and cues key aspects of Pseudomonas aeruginosa physiology. J. Bacteriol. 187, 5267-5277 (2005).

43. Nguyen, C. T. et al. Noninvasive in vivo optical detection of biofilm in the human middle ear. Proc. Natl Acad. Sci. USA 109, 9529-9534 (2012).

44. Xi, C.W., Marks, D., Schlachter, S., Luo, W. \& Boppart, S.A. High-resolution threedimensional imaging of biofilm development using optical coherence tomography. J. Biomed. Opt. 11, https://doi.org/10.1117/1.2209962 (2006).

45. Huang, D. et al. Optical coherence tomography. Science 254, 1178-1181 (1991).

46. Levitz, D. et al. Quantitative characterization of developing collagen gels using optical coherence tomography. J. Biomed. Opt. 15, 026019 (2010).

47. Vroom, J. M. et al. Depth penetration and detection of $\mathrm{pH}$ gradients in biofilms by two-photon excitation microscopy. Appl. Environ. Microbiol. 65, 3502-3511 (1999).

48. Morris, R. L. \& Schmidt, T. M. Shallow breathing: bacterial life at low O(2). Nat. Rev. Microbiol. 11, 205-212 (2013).

49. Gosmann, B. \& Rehm, H. J. Oxygen-uptake of microorganisms entrapped in Caalginate. Appl. Microbiol. Biot. 23, 163-167 (1986).

50. Chen, J. \& Strous, M. Denitrification and aerobic respiration, hybrid electron transport chains and co-evolution. Biochim. Biophys. Acta 1827, 136-144 (2013).

51. Strohm, T. O., Griffin, B., Zumft, W. G. \& Schink, B. Growth yields in bacterial denitrification and nitrate ammonification. Appl. Environ. Microbiol. 73, 1420-1424 (2007).

52. Eschbach, M. et al. Long-term anaerobic survival of the opportunistic pathogen Pseudomonas aeruginosa via pyruvate fermentation. J. Bacteriol. 186, 4596-4604 (2004).

53. Schreiber, K. et al. Anaerobic survival of Pseudomonas aeruginosa by pyruvate fermentation requires an Usp-type stress protein. J. Bacteriol. 188, 659-668 (2006).

54. Vander Wauven, C., Pierard, A., Kley-Raymann, M. \& Haas, D. Pseudomonas aeruginosa mutants affected in anaerobic growth on arginine: evidence for a four-gene cluster encoding the arginine deiminase pathway. J. Bacteriol. 160, 928-934 (1984). 
55. Ploug, H., Kuhl, M., BuchholzCleven, B. \& Jorgensen, B. B. Anoxic aggregates-an ephemeral phenomenon in the pelagic environment? Aquat. Microb. Ecol. 13, 285-294 (1997).

56. Robertson, L. A. \& Kuenen, J. G. Aerobic denitrification-old wine in new bottles? Antonie Van Leeuwenhoek 50, 525-544 (1984).

57. Alvarez-Ortega, C. \& Harwood, C. S. Responses of Pseudomonas aeruginosa to low oxygen indicate that growth in the cystic fibrosis lung is by aerobic respiration. Mol. Microbiol. 65, 153-165 (2007).

58. Ettwig, K. F. et al. Nitrite-driven anaerobic methane oxidation by oxygenic bacteria. Nature 464, 543-548 (2010).

59. Staal, M., Borisov, S. M., Rickelt, L. F., Klimant, I. \& Kuhl, M. Ultrabright planar optodes for luminescence life-time based microscopic imaging of $\mathrm{O} 2$ dynamics in biofilms. J. Microbiol. Methods 85, 67-74 (2011).

60. Borriello, G., Richards, L., Ehrlich, G. D. \& Stewart, P. S. Arginine or nitrate enhances antibiotic susceptibility of Pseudomonas aeruginosa in biofilms. Antimicrob. Agents Chemother. 50, 382-384 (2006).

61. Kolpen, M. et al. Reinforcement of the bactericidal effect of ciprofloxacin on Pseudomonas aeruginosa biofilm by hyperbaric oxygen treatment. Int. J. Antimicrob. Agents 47, 163-167 (2016).

62. Bjarnsholt, T. et al. Pseudomonas aeruginosa tolerance to tobramycin, hydrogen peroxide and polymorphonuclear leukocytes is quorum-sensing dependent. Microbiology 151, 373-383 (2005).

63. Fujimoto, J. G., Pitris, C., Boppart, S. A. \& Brezinski, M. E. Optical coherence tomography: an emerging technology for biomedical imaging and optical biopsy. Neoplasia 2, 9-25 (2000).

64. Wangpraseurt, D., Wentzel, C., Jacques, S.L., Wagner, M. \& Kühl, M. In vivo imaging of coral tissue and skeleton with optical coherence tomography. J. R. Soc. Interface 14, https://doi.org/10.1098/rsif.2016.1003 (2017).
65. Mater, D. D. G., Barbotin, J. N., Saucedo, J. E. N., Truffaut, N. \& Thomas, D. Effect of gelation temperature and gel-dissolving solution on cell viability and recovery of 2 Pseudomonas putida strains co-immobilized within calcium alginate or $\mathrm{k}$ carrageenan gel beads. Biotechnol. Tech. 9, 747-752 (1995).

66. de Beer, D., Stoodley, P. in The Prokaryotes (eds Dworkin, M., Falkow, S., Rosenberg, E., Schleifer, K.H., Stackebrandt, E.) 904-937 (Springer Science, New York, 2006).

67. Broecker, W. S. \& Peng, T. H. Gas-exchange rates between air and sea. Tellus 26, 21-35 (1974).

68. Elgetti Brodersen, K., Koren, K., Lichtenberg, M. \& Kuhl, M. Nanoparticle-based measurements of $\mathrm{pH}$ and $\mathrm{O}_{2}$ dynamics in the rhizosphere of Zostera marina L.: effects of temperature elevation and light-dark transitions. Plant Cell Environ. 39, 1619-1630 (2016).

(i) Open Access This article is licensed under a Creative Commons Attribution 4.0 International License, which permits use, sharing, adaptation, distribution and reproduction in any medium or format, as long as you give appropriate credit to the original author(s) and the source, provide a link to the Creative Commons license, and indicate if changes were made. The images or other third party material in this article are included in the article's Creative Commons license, unless indicated otherwise in a credit line to the material. If material is not included in the article's Creative Commons license and your intended use is not permitted by statutory regulation or exceeds the permitted use, you will need to obtain permission directly from the copyright holder. To view a copy of this license, visit http://creativecommons. org/licenses/by/4.0/.

(c) The Author(s) 2018 